\title{
Comparative mitogenomic analysis of mirid bugs (Hemiptera: Miridae) and evaluation of potential DNA barcoding markers
}

\author{
Juan Wang $^{1}$ ， Li Zhang ${ }^{1}$ ， Qi-Lin Zhang ${ }^{1}$ ， Min-Qiang Zhou ${ }^{1}$ ， Xiao-Tong Wang ${ }^{1}$, Xing-Zhuo Yang ${ }^{1}$, Ming- \\ Long Yuan Corresp. 1 \\ ${ }^{1}$ State Key Laboratory of Grassland Agro-Ecosystems, College of Pastoral Agricultural Science and Technology, Lanzhou University, Lanzhou, China \\ Corresponding Author: Ming-Long Yuan \\ Email address: yuanml@Izu.edu.cn
}

The family Miridae is one of the most species-rich families of insects. To better understand the diversity and evolution of mirids, we determined the mitogenome of Lygus pratenszs and re-sequenced the mitogenomes of four mirids (i.e. Apolygus lucorum, Adelphocoris suturalis, Ade. fasciaticollis and Ade. lineolatus). We performed a comparative analysis for 15 mitogenomic sequences representing 11 species of five genera within Miridae and evaluated the potential of these mitochondrial genes as molecular markers. Our results showed that the general mitogenomic features (gene content, gene arrangement, base composition and codon usage) were well conserved among these mirids. Four proteincoding genes (PCGs) (cox1, cox3, nad1 and nad3) had no length variability, where nad5 showed the largest size variation; no intraspecific length variation was found in PCGs. Two PCGs (nad4 and nad5) showed relatively high substitution rates at the nucleotide and amino acid levels, where cox1 had the lowest substitution rate. The Ka/Ks values for all PCGs were far lower than one $(<0.59)$, but the $K a / K s$ values of cox 1 -barcode sequences were always larger than 1 (1.34 - 15.20), indicating that the 658 bp sequences of cox 1 may be not the appropriate marker due to positive selection or selection relaxation. Phylogenetic analyses based on two concatenated mitogenomic datasets consistently supported the relationship of Nesidiocoris + (Trigonotylus + (Adelphocoris + (Apolygus + Lygus))), as revealed by nad4, nad5, rrnL and the combined 22 transfer RNA genes (tRNAs), respectively. Taken sequence length, substitution rate and phylogenetic signal together, the individual genes ( $n a d 4$, nad5 and $r r n L$ ) and the combined 22 tRNAs could been used as potential molecular markers for Miridae at various taxonomic levels. Our results suggest that it is essential to evaluate and select suitable markers for different taxa groups when performing phylogenetic, population genetic and species identification studies. 


\section{Research article}

2

3 Comparative mitogenomic analysis of mirid bugs (Hemiptera: Miridae) and

4 evaluation of potential DNA barcoding markers

5

6 Juan Wang§, Li Zhang§, Qi-Lin Zhang§, Min-Qiang Zhou, Xiao-Tong Wang, Xing-Zhuo Yang,

7 Ming-Long Yuan*

8

9 State Key Laboratory of Grassland Agro-Ecosystems, College of Pastoral Agricultural Science

10 and Technology, Lanzhou University, Lanzhou, Gansu 730020, People's Republic of China

12 §These authors contributed equally to this work.

$14{ }^{*}$ Correspondence and requests for materials should be addressed to M.L.Y. (yuanml@1zu.edu.cn) 


\section{Abstract}

18 The family Miridae is one of the most species-rich families of insects. To better understand the diversity and evolution of mirids, we determined the mitogenome of Lygus pratenszs and resequenced the mitogenomes of four mirids (i.e. Apolygus lucorum, Adelphocoris suturalis, Ade. fasciaticollis and Ade. lineolatus). We performed a comparative analysis for 15 mitogenomic sequences representing 11 species of five genera within Miridae and evaluated the potential of these mitochondrial genes as molecular markers. Our results showed that the general mitogenomic features (gene content, gene arrangement, base composition and codon usage) were well conserved among these mirids. Four protein-coding genes (PCGs) (coxl, cox3, nadl and nad3) had no length variability, where nad5 showed the largest size variation; no intraspecific length variation was found in PCGs. Two PCGs (nad4 and nad5) showed relatively high substitution rates at the nucleotide and amino acid levels, where coxl had the lowest substitution rate. The $\mathrm{Ka} / \mathrm{Ks}$ values for all PCGs were far lower than one $(<0.59)$, but the $\mathrm{Ka} / \mathrm{Ks}$ values of coxl-barcode sequences were always larger than $1(1.34-15.20)$, indicating that the $658 \mathrm{bp}$ sequences of coxl may be not the appropriate marker due to positive selection or selection relaxation. Phylogenetic analyses based on two concatenated mitogenomic datasets consistently supported the relationship of Nesidiocoris $+($ Trigonotylus $+($ Adelphocoris $+($ Apolygus + Lygus))), as revealed by $n a d 4, n a d 5, r r n L$ and the combined 22 transfer RNA genes (tRNAs), respectively. Taken sequence length, substitution rate and phylogenetic signal together, the individual genes (nad4, nad5 and $r r n L$ ) and the combined 22 tRNAs could been used as potential molecular markers for Miridae at various taxonomic levels. Our results suggest that it is essential 
38 to evaluate and select suitable markers for different taxa groups when performing phylogenetic, 39 population genetic and species identification studies. 


\section{Introduction}

42 Mirid bugs (Hemiptera: Miridae) are one of the most species-rich families of insects, with

43 approximately 11,000 described species in 1,200 genera (Cassis \& Schuh 2012; Jung \& Lee

44 2012). Mirid bugs play a key role in natural systems and agroecosystems, with a wide range of

45 food preferences and behaviors (Cassis \& Schuh 2012; Jung \& Lee 2012; Wheeler 2001). Some

46 mirids are of great economic importance as pests on various cultivated plants (Cassis \& Schuh

47 2012; Lu et al. 2010), whereas others are beneficial species used as biological control agents

48 (Cassis \& Schuh 2012). In China, several mirids (e.g. Apolygus lucorum, Lygus pratenszs and

49 Adelphocoris lineolatus) are important insect pests on crops, vegetables and forages and recently

have extensively increased population density on cotton due to increasing Bt cotton adoption ( $\mathrm{Lu}$

et al. 2010). However, little is known about interspecific and intraspecific diversity and evolution in these mirids.

Mirids show high morphological diversity and some are difficult to be identified by eye due to small body size, especially closely related species with similar morphological characteristics. The mitochondrial cytochrome c oxidase subunit 1 ( $\operatorname{cox} 1)$ has been widely used as a molecular marker for molecular phylogenetics, population genetics and species identification in animals

57 (Avise 2009; Hebert et al. 2003; Jinbo et al. 2011; Simon et al. 2006). The effectiveness of cox 1 as a DNA barcoding marker has been widely investigated in many insect groups, such as Lepidoptera (Cameron \& Whiting 2008; Mitchell et al. 2010; Wiemers \& Fiedler 2007), Hemiptera (Abd-Rabou et al. 2012; Foottit et al. 2008; Jung et al. 2011; Park et al. 2011; 
62 2010). These studies showed that coxl was an effective and suitable DNA barcoding marker for

63 most insect groups, but showed limited ability to identify closely related species for some groups

64 (MeiYan et al. 2012; Lee et al. 2013; Schmidt \& Sperling 2008). Therefore, it is essential to explore other potential mitochondrial and nuclear markers for these groups, such as nuclear ITS (Park et al. 2010) and other mitochondrial genes (e.g. nad4 and nad5) (Brabec et al. 2015; contains 37 genes and a large non-coding region (known as control region) (Boore 1999; Cameron 2014). During the past decades, insect mitogenomes are the most extensively used genetic information for molecular evolutionary, phylogenetic and population genetic studies (Cameron 2014; Simon et al. 2006). To date, only ten complete or nearly complete mitogenomes have been determined for Miridae. However, the number of sequenced mirid mitogenomes is still very limited compared to the species-richness of Miridae. Therefore, sequencing more mirid mitogenomes is essential for understanding the evolution of Miridae at the genomic level. In particular, all mirid mitogenomes available in GenBank were sequenced for just a single individual per species, which limited our understanding of intraspecific mitogenomic diversity. To date, knowledge about intraspecific evolution of insect mitogenomes is limited, with the notable exception of Drosophila melanogaster (Wolff et al. 2016). Due to the linkage of these mitochondrial genes within the same mtDNA molecule, the same genealogy shared by mitochondrial genes is expected. However, incongruent phylogenetic results were frequently found among different mitochondrial genes (Duchêne et al. 2011; Havird \& Santos 2014; Nadimi 
83

84

85

86

87

et al. 2016). In addition, the single or a few concatenated genes could serve as a proxy for the entire mitogenomes (Duchêne et al. 2011; Havird \& Santos 2014; Nadimi et al. 2016), which provides a good opportunity to resolve phylogenetic relationships of Miridae that currently lacks sufficient entire mitogenome sequences. However, the performance of the best genes or regions is highly taxa-dependent (Duchêne et al. 2011; Havird \& Santos 2014; Nadimi et al. 2016). Therefore, it is needed to evaluate the potential and suitability of single mitochondrial genes as molecular markers within Miridae.

In this study, we sequenced and annotated the mitogenome of $L$. pratenszs and re-sequenced the mitogenomes of four mirid species (i.e. Apo. lucorum, Ade. suturalis, Ade. fasciaticollis and Ade. lineolatus). These five mirid bugs are important pests on crops, vegetables and forages in China (Lu et al. 2010; Zhang et al. 2016). Combined with ten mirid mitogenomes available from GenBank (Table 1), we provided a comparative mitogenomic analysis at various taxonomic levels. Particularly, we focused on molecular evolution of mitochondrial genes within genera and species. We also evaluated the potential of these mitochondrial genes as molecular markers by genetic distance and phylogenetic analyses. The results will provide useful genetic information for further studies on phylogeny, species identification, phylogeography and population genetics in mirid bugs.

Materials and Methods

\section{Sample and DNA extraction}

Adult specimens of five mirid bugs were collected from alfalfa field in Shishe Town, Xifeng 
104 District, Qingyang City, Gansu Province, China, in July 2013. Samples and voucher specimens

105 have been deposited in the State Key Laboratory of Grassland Agro-Ecosystems, College of

106 Pastoral Agricultural Science and Technology, Lanzhou University, Lanzhou, China. All

107 specimens were initially preserved in $100 \%$ ethanol in the field, and transferred to $-20^{\circ} \mathrm{C}$ until

108

109

110

111

112

113

114

115

116

117

118

119

120

121

122

123

124

used for DNA extraction. The total genomic DNA was extracted from thorax muscle of a single specimen using the OMEGA Insect DNA Kit (OMEGA, USA) according to the manufacturer's protocols.

\section{PCR amplification and sequencing}

For each mirid species, mitogenome was amplified with 10-13 overlapping fragments by using universal insect mitogenome primers (Simon et al. 2006) and species-specific primers designed from sequenced fragments. All primers used in this study are provided in Table S1. PCR and sequence reactions were conducted following our previous studies (Yuan et al. 2015a; Yuan et al. 2015b).

\section{Genome annotation and sequence analysis}

Sequence files were assembled into contigs with BioEdit 7.0.9.0 (Hall 1999). Each of the five mirid mitogenomes newly sequenced in the present study was annotated following our previous studies (Yuan et al. 2015a; Yuan et al. 2015b). Nucleotide composition and codon usage were analyzed with MEGA 6.06 (Tamura et al. 2013). For each protein-coding gene (PCG) of all 15 mirid mitogenomes, the number of synonymous substitutions per synonymous site (Ks) and the 
125

126

127

128

129

130

131

132

133

134

135

136

137

number of nonsynonymous substitutions per nonsynonymous site (Ka) were calculated with MEGA 6.06 (Tamura et al. 2013). We also calculated the genetic distances for 13 PCGs and two ribosomal RNA genes (rRNAs) with MEGA 6.06 (Tamura et al. 2013) under the Kimura-2parameter model (K2P). Strand asymmetry was calculated using the formulas: AT-skew $=[\mathrm{A}-$ $\mathrm{T}] /[\mathrm{A}+\mathrm{T}]$ and GC-skew $=[\mathrm{G}-\mathrm{C}] /[\mathrm{G}+\mathrm{C}]($ Perna $\&$ Kocher 1995). To determine whether the $\mathrm{Ka} / \mathrm{Ks}$ values of coxl-barcode sequences were relevant with the scope of sequences used, we downloaded all 7759 coxl sequences of Miridae available in GenBank (March 1, 2017 ). After removing sequences shorter than $658 \mathrm{bp}$, a total of 2326 sequences in 144 genera were obtained (Table S7). Except for forty genera with only one sequence, the remaining 104 genera were used to calculate the values of $\mathrm{Ka}, \mathrm{Ks}$ and $\mathrm{Ka} / \mathrm{Ks}$.

\section{Phylogenetic analysis}

Complete or nearly complete mitogenome sequences of eleven mirid bugs (15 samples, Table 1) and two outgroups from Pentatomomorpha (Corizus tetraspilus and Eurydema gebleri) (Yuan et al. 2015a; Yuan et al. 2015b) were used to perform phylogenetic analyses. The complete sequences of 13 PCGs (excluding stop codons), two rRNAs and 22 transfer RNA genes (tRNAs) were used for phylogenetic analyses. Each PCG was aligned individually based on codon-based multiple alignments by using the MAFFT algorithm within the TranslatorX (Abascal et al. 2010) online platform. Sequences of each rRNA gene were individually aligned using the MAFFT v7.0 online server with G-INS-i strategy (Katoh \& Standley 2013). Alignments of individual genes were then concatenated as a combined matrix with DAMBE 5.3.74 (Xia 2013). Two datasets 
146

147

148

150

151

152

153

154

155

156

157

158

159

160

161

162

163

164

165

166

were assembled for phylogenetic analyses: (1) nucleotide sequences of 13 PCGs (P123) with

11,133 residues and (2) nucleotide sequences of 13 PCGs, two rRNAs and 22 tRNAs (P123RT)

with 14,905 residues. To evaluate phylogenetic potential of single mitochondrial genes, i.e. each

of 13 PCGs, $r r n L$ and $r r n S$, as well as the combined 22 tRNAs, were also used in phylogenetic

analyses.

The optimal partitioning schemes and corresponding nucleotide substitution models for each datasets were determined by PartitionFinder v1.1.1 (Lanfear et al. 2012). We created input configuration files that contained pre-defined data blocks by genes and codons, e.g. 39 partitions for P123, 42 partitions for P123RT and 3 partitions for each of 13 PCGs. The "'greedy" algorithm with branch lengths estimated as "unlinked"' and Bayesian information criterion (BIC) were used to search for the best-fit scheme (Table S2). The best-fit partitioning schemes selected by PartitionFinder were used in all subsequent phylogenetic analyses. We used jModelTest 2.1.7 (Posada 2008) to determine the best evolutionary model for $r r n L, r r n S$ and the combined 22 tRNAs.

Phylogenetic analyses were conducted with Bayesian inference (BI) and maximum likelihood (ML) methods available on the CIPRES Science Gateway v3.3 (Miller et al. 2010). Bayesian analyses were performed with MrBayes 3.2.3 (Ronquist et al. 2012) on Extreme Science and Engineering Discovery Environment (XSEDE 8.0.24). Two independent runs with four chains (three heated and one cold) each were conducted simultaneously for $1 \times 10^{6}$ generations. Each run was sampled every 100 generations. Stationarity is assumed to be reached when ESS (estimated sample size) value is above 100 and PSRF (potential scale reduction factor) 
167

168

169

170

171

172

173

174

175

176

177

178

179

180

181

182

183

184

185

186

187

approach 1.0 as suggested in MrBayes 3.2.3 manual (Ronquist et al. 2012). The first 25\%

samples were discarded as burn-in, and the remaining trees were used to calculate posterior probabilities (PP) in a 50\% majority-rule consensus tree. ML analyses were carried out using RAxML-HPC2 (Stamatakis 2014) on XSEDE 8.0.24 with the GTRGAMMA model, and the node reliability was assessed by 1,000 bootstraps (BS).

\section{Results}

\section{General features of mirid mitogenomes}

In the present study, we sequenced and annotated the mitogenomes of five mirid bugs: two were completely sequenced, whereas three were nearly complete mitogenomes (lacking sequences of three tRNAs and the putative control region) (Table 1, Table S3). The mitogenome sequences of five mirids have been deposited in GenBank of NCBI under accession numbers: KU234536KU234540. The two completely sequenced mitogenomes contained 37 typical mitochondrial genes (i.e. 13 PCGs, 22 tRNA genes and two rRNAs) and a large non-coding region (putative control region) (Table S3). The order and orientation of the mitochondrial genes were identical to that of the putative ancestral insect mitogenome (Boore 1999; Cameron 2014). Gene overlaps and spacers were presented in several conserved positions in the mirid mitogenomes, e.g. trnS2/nad1 (7 bp), trnW/trnC (-8 bp), atp8/atp6 (-7 bp) and nad4/nad4L (-7 bp).

$$
\text { The tRNAs in the three Adelphocoris species could be folded into a classical clover-leaf }
$$
secondary structure (Figure 1). However, trnSl(AGN) in Apo. lucorum and L. pratenszs species lacked the DHU stem-loop structures, as previously observed in many other true bugs (Wang et 
188

189

190

191

al. 2014b; Yuan et al. 2015a; Yuan et al. 2015b). All 22 tRNAs in Apolygus and Lygus species used the standard anticodon, whereas two tRNAs in the three Adelphocoris species were exceptions: $\operatorname{trnS} 1$ was predicted to have anticodon UCU, whereas $\operatorname{trn} K$ had the anticodon UUU (Table S3). The sequences and structures of anticodon arms and aminoacyl acceptor stems were well conserved within Miridae, whereas most of the variations (nucleotide substitutions and

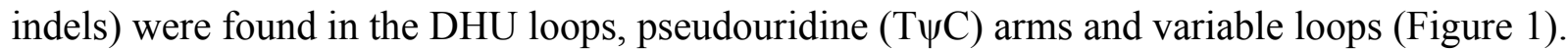
All of the mirid mitogenomes showed similar nucleotide composition in the J-strand: high $\mathrm{A}+\mathrm{T}$ content, positive AT- and negative GC-skews (Figure S1), as is usually observed in insect mitogenomes (Hassanin et al. 2005). For each part of mitogenomes, the A+T content, AT- and GC-skews showed low variability among different taxonomic levels (i.e. family, subfamily, genus and species). For AT-skew, a negative value was found in PCGs, $r r n L, r r n S$ and the 2nd codon position of PCGs, whereas the 1st and 3rd codon positions of PCGs had positive AT-skew values. Except for Apo. lucorum, a positive AT-skew value also was found for tRNAs in all mirids. For GC-skew, the 1st codon position of PCGs, $r r n L$, $r r n S$ and tRNAs were markedly positive, whereas the 2 nd and 3 rd codon positions of PCGs showed negative values. The pattern of codon usage in all analyzed mirid mitogenomes was consistent with previous findings in insects (e.g. Wang et al. 2015; Yuan et al. 2015a), namely that A+T-rich codons were preferably used (Table S4).

\section{Gene variability in mirid mitogenomes}

Among 13 PCGs, four genes (cox1, cox3, nad1 and nad3) had no length variability in the 15 
209

210

211

212

213

214

215

216

217

218

219

220

221

222

223

224

225

226

227

228

229

examined mirid mitogenomes (Table S5). Four genes showed size variation only in one species

(i.e. atp6, cox2 and nad4 in N. tenuis, cob in L. lineolaris). N. tenuis belonging to Bryocorinae

showed the most length differences with species from Mirinae. The length of nad5 was most

variable, but conserved within each genus. No length variation was found in the same species,

whereas the most variations were found among genera. For the two genera including more than

two species, no size variation was present in Adelphocoris, and only cob in L. lineolaris showed

size difference with the others in Lygus. For $r r n L$ and $r r n S$, intra-generic and -specific size

differences were slight, whereas large differences were found among genera.

The numbers of variable and informative sites varied among genes and taxa (Table 2). The

smallest gene atp 8 showed the highest informative sites in Miridae, Mirinae and Mirini, followed

by nad2 and nad6, while nad4L in Adelphocoris and nad3 in Lygus. The coxl gene showed least

informative sites in Miridae, Mirinae and Mirini, while nad6 in Adelphocoris and nad4L in

Lygus. Generally, rrnL and $r r n S$ had the lower informative sites than most PCGs; $r r n L$ was

slightly higher than $r r n S$, except for Adelphocoris. Compared to the whole cox 1, coxl-barcode

sequences contained relatively small informative sites in most taxonomic levels (except for

Lygus). Except for coxl, other two longest genes (nad4 and nad5) contained moderate

informative sites in most taxonomic levels (except for Lygus).

As expected, the largest genetic distances were found among subfamilies, followed by

Tribes and genera, whereas the smallest among species (Figure 2). Some genes (e.g. atp6, cox2, nad1, nad3 and nad6) showed no intraspecific variations at nucleotide and/or amino acid levels, indicating that these genes were highly conserved. The values of K2P and Ka in 13 PCGs of 
Lygus were larger than that of Adelphocoris, indicating that Lygus had the higher substitution

rates. For the K2P distance, nad6 was the highest in Miridae and Lygus, whereas atp8 in Mirinae

232 and Mirini. The K2P distance of nad4L was the highest within Adelphocoris, and relatively high

233 K2P distance was also found in Miridae, Mirinae, Mirini and Lygus. The two rRNAs showed

234 similar K2P distance with those of $\operatorname{cox} 1-3$ and $c o b$ in Miridae, Mirinae and Mirini, but had the

235 lowest substitution rates in Lygus. For Miridae, Mirinae and Mirini, atp 8 showed the highest Ka

236 value, whereas nad4L in Adelphocoris and nad6 in Lygus showed the highest Ka values. Two

237 genes (nad4 and nad5) showed relatively high substitution rates at the nucleotide and amino acid

238 levels. Cox 1 showed the lowest substitution rate in Miridae, Mirinae, Mirini, Adelphocoris and

239 Lygus. The Ka/Ks values for all PCGs were far lower than one $(<0.59)$ (Figure 2), suggesting

that these genes were evolving under purifying selection. However, we found that the $\mathrm{Ka} / \mathrm{Ks}$

values for coxl-barcode sequences of the 15 mirids were always larger than 1 (1.34 in Ade.

suturalis to 15.20 in Mirini; Table S6). In addition, analyses for cox l-barcode sequences of

Miridae from GenBank showed that forty-four genera had no Ka and/or Ks values (Table S7),

whereas the values of $\mathrm{Ka} / \mathrm{Ks}$ for the remaining 61 genera were larger than one (1.5-263.0, Table

S7), indicating that these sequences may be under positive selection or selection relaxation

during the evolutionary process of Miridae. These results suggested that different genes had differences. 
251

252

253

254

255

256

257

258

259

260

261

262

263

264

265

266

267

268

269

270

271

Phylogenetic relationships of 15 mirid mitogenome sequences were inferred using BI and ML methods based on two mitogenomic datasets (P123 and P123RT). The results showed that the two methods with the same dataset resulted in identical tree topology, whereas slight difference was found in the relationships of three species between the two datasets (Figure 3). For the P123 dataset, Ade. nigritylus was sister to Ade. suturalis $(\mathrm{PP}=0.65, \mathrm{BS}=84)$. For the $\mathrm{P} 123 \mathrm{RT}$ dataset, Ade. nigritylus had a closer relationship with Ade. fasciaticolli and Ade. lineolatus ( $\mathrm{PP}=0.64$, $\mathrm{BS}=30$ ), which was consistent with previous mirid phylogeny based on mitogenomic data (Wang et al. 2014b). However, low supports were present in both analyses (Figure 3), indicating that the phylogenetic position of Ade. nigritylus was unstable. All analyses consistently supported the relationship of Nesidiocoris + (Trigonotylus $+($ Adelphocoris $+($ Apolygus + Lygus))), as previous mitogenomic analyses (Wang et al. 2014b). For Lygus, the two datasets consistently recovered a phylogeny of (rugulipennis $+($ lineolaris $+($ hesperus + pratenszs $)))$.

The monophyly of Adelphocoris was strongly supported by all analyses with high supports ( $\mathrm{PP}=$ $1.0, \mathrm{BS}=100)$, as was the monophyly of Lygus $(\mathrm{PP}=1.0, \mathrm{BS}=100)$.

\section{Mirid phylogeny based on single mitochondrial gene}

We performed phylogenetic analyses using BI and ML methods with single mitochondrial genes, including each of 13 PCGs, $r r n L, r r n S$ and the combined 22 tRNAs (Figures S2 and S3).

The results showed that the tree topologies were variable among different datasets, indicating incongruent phylogenetic signals among genes, as reported in previous similar studies (Duchêne et al. 2011; Havird \& Santos 2014; Nadimi et al. 2016). However, all analyses consistently 
272 supported the monophyly of each of Adelphocoris (PP $=0.87-1.0, \mathrm{BS}=82-100)$ and Lygus (PP

$273=0.74-1.0, \mathrm{BS}=59-100)$, and several relationships within each of these two genera were

274 recovered by different individual genes (Table 3, Figures S2 and S3). Four datasets (nad4, nad5,

275 rrnL and tRNAs) with the two analytical methods supported the phylogeny: Nesidiocoris +

276 (Trigonotylus $+($ Adelphocoris $+($ Apolygus + Lygus $)))$, as recovered by the P123 and P123RT

277 datasets. This relationship among the five genera was also supported by BI analyses with two

278 other genes (coxl and nad2). These four datasets supported the Lygus phylogeny of

279 (rugulipennis $+($ lineolaris $+($ hesperus + pratenszs $)))$, as four other genes $($ cob, cox3, nadl and

280 nad6). For Adelphocoris, BI and ML analyses of four genes (cox2, cox3, nad5 and rrnL)

281 supported (fasciaticollis + lineolatus $)+$ nigritylus $(\mathrm{PP}=0.85-1.0, \mathrm{BS}=34-98)$, whereas other

282 four genes (atp6, coxl, nad1 and nad4) recovered the sister relationship of nigritylus and

283 suturalis $(\mathrm{PP}=0.63-0.9, \mathrm{BS}=53-97)$. It was notable that the coxl-barcode sequences did not

284 support the sister relationship of Apolygus + Lygus consistently recovered by many independent

285 datasets (Figure 3 and Figures S2-S4).

\section{Discussion}

To date, a total of 15 mitogenomes representing 11 species in five genera were sequenced

for Miridae. For the seven nearly complete mitogenomes, the undetermined region was the

control region characterized by notable base composition bias, high numbers of tandem repeats

and stable stem-loop structures. These features may result in disruption of PCR and sequencing 
293 size of completely sequenced mitogenomes greatly varied among genera, ranging from 14,522

294 bp in Ade. nigritylus and 17,747 bp in L. hesperus, primarily due to the significant size variation

295 of the control region. The complete mitogenome of Apo. lucorum $(15,647 \mathrm{bp})$ re-sequenced in

296 the present study was rather larger than that previously sequenced by Wang et al. (2014a)

$297(14,768 \mathrm{bp})$, largely due to significant size difference between the two control regions. Sequence

298 alignment of control regions found that Apo. lucorum previously sequenced lacked regions of

299

300

301

302

303

304

305

306

307

308

309

310

311

312

313 multiple repeated sequences, implying that the control region may be incomplete. The two completely sequenced mitogenomes of Ade. lineolatus were highly similar in length, with a 162 bp difference. Generally, genome size and total length of spacers and overlaps were more conserved within genus and species than that within subfamily and family, as reported in previous similar studies (Roehrdanz et al. 2016; Wang et al. 2014a; Wang et al. 2014b; Wang et al. 2016a).

The loss of the DHU arm in trnS1 (AGN) has been considered a typical feature of insect mitogenomes (Cameron 2014). It has been shown that in the nematode Ascaris suum the tRNA genes that lack the DHU arm are functional (Okimoto et al. 1992). We found that trnS1 in Apo. lucorum and L. pratenszs species lacked the DHU arm, but this tRNA in all sequenced mitogenomes of Adelphocoris species had a classical clover-leaf secondary structure, indicating the diversity in the secondary structures of $\operatorname{trnS} 1$ within miridae. With the exception of $\operatorname{trn} S 1$ and $\operatorname{trnK}$, all the remaining 20 tRNAs used the same anticodon in mirids as in other hemipterans (Wang et al. 2015; Yuan et al. 2015a; Yuan et al. 2015b). In the four Adelphocoris species, trnS1 changed the anticodon GCU with UCU and trnK changed the anticodon CUU with UUU. We re- 
314 sequenced the mitogenomes of three Adelphocoris species, confirming that the two anticodons of

$315 \operatorname{trnS1}$ and $\operatorname{trn} K$ were genus-specific conserved. Therefore, the variations in structures and

316 anticodons of mirid tRNAs may be genus-specific, and may indicate the high species diversity of

317 Miridae. The mutations in the $\operatorname{trnS1}$ and $\operatorname{trn} K$ anticodons were uncommon in hemipteran

318 mitogenomes, which may be correlated with the AGG codon reassignments between serine and

319 lysine (Abascal et al. 2006; Wang et al. 2014b). We also noticed that trnS1 in coleopteran

mitogenomes always used the anticodon UCU (Sheffield et al. 2008; Yuan et al. 2016) and trnK

used UUU in some beetles (Li et al. 2016; Wang et al. 2016b), suggesting the parallel evolution

of AGG codon reassignments and point mutations at the anticodons of $\operatorname{trnS} 1 / \operatorname{trnK}$ in insect

mitogenomes (Abascal et al. 2006; Wang et al. 2014b). Further study by sequencing more

mitogenomes from other genera and species is needed to investigate the evolution of anticodons

and structures within Miridae.

Currently, coxl has been extensively used as DNA barcoding for evaluating and resolving

phylogenetic relationships in insects (Hebert et al. 2003; Jinbo et al. 2011). Although the whole

coxl sequences were evolving under purifying selection, the $\mathrm{Ka} / \mathrm{Ks}$ values of the coxl-barcode

sequences were always larger than one at various taxonomic levels within Miridae. Therefore,

when we aim to determine the neutral population structure of mirids, the whole cox 1 sequences,

combined other mitochondrial genes (e.g. nad4 and nad5) as well as other markers (e.g.

microsatellites and SNPs), may be preferred. In contrast, the coxl-barcode sequences may have 
335

336

337

338

339

340

341

342

343

344

345

346

347

348

349

350

351

352

353

354

355

Bayesian methods) are essential to reveal evolutionary patterns of coxl-barcode sequences within Miridae.

Phylogenetic analyses indicated that individual genes supported different phylogenetic relationships of the 15 mirids despite their linked nature, as reported in previous studies (Duchêne et al. 2011; Havird and Santos 2014; Nadimi et al. 2016; Seixas et al. 2016). The most probable factor for these incongruent phylogenies is the lack of adequate phylogenetic information within each individual gene, but other potential factors (e.g. phylogenetic inference methods, incomplete taxon sampling) should be considered. Two PCGs (nad4 and nad5) consistently supported the same relationships among the five genera and the four Lygus species, as the two concatenated mitogenomic datasets. These two genes were also identified as good molecular markers for metazoan phylogenetic analyses (Havird and Santos 2014). However, most previous studies focused on the phylogenetic performance of mitochondrial PCGs, whereas the phylogenetic potential of RNA genes were rarely assessed by comparing the performance of single and concatenated mitochondrial genes. In the present study, we found that $r r n L$ and the combined 22 tRNAs performed well in phylogenetic analyses, as nad4 and nad5, suggesting their potential and importance in resolving the phylogeny of Miridae. However, we found that although coxl probably was the most commonly used mitochondrial genes in studies of metazoans, this gene (especially coxl-barcode sequences) showed poor phylogenetic performance within Miridae, indicating that the coxl sequences provided phylogenetic signals that may not be representative of the other mitochondrial genes in Miridae. Previous studies showed incongruent phylogenetic results of $\operatorname{cox} l$ sequences, suggesting that the suitability of 
356 coxl may be taxa-specific and relevant to species number used (Havird and Santos 2014).

357 Therefore, we should be cautious when the phylogenies are solely derived from sequence data of

358 coxl, whereas additional mitochondrial genes could provide useful genetic information for

359 phylogenetics and population genetics studies of mirid bugs.

360

361 Conclusions

362 In this study, we determined the mitogenomes of L. pratenszs and re-sequenced other four mirid mitogenomes, and provided a comparative analysis for all 15 sequenced mitogenomes at various taxonomic levels. The results showed that gene content, gene arrangement, codon usage and nucleotide composition were well conserved within Miridae. Four protein-coding genes (coxl, cox3, nad1 and nad3) had no length variability, where nad5 showed the most size variation; no intraspecific length variation was found in PCGs. Two genes (nad4 and nad5) showed relatively

high substitution rates and informative sites in most taxonomic levels, where cox 1 had the lowest in Miridae, Mirinae and Mirini. Taken sequence length, substitution rate and phylogenetic signal together, the individual genes (nad4, nad5 and $r r n L$ ) and the combined dataset of 22 tRNAs could be used as potential molecular markers for Miridae. Our results suggest that it is essential to evaluate and select suitable markers for different taxa groups when performing phylogenetic and population genetic studies.

\section{DNA Deposition}

The following information was supplied regarding the deposition of DNA sequences: 
377 The mitogenomes of five mirids are deposited in GenBank of NCBI under accession numbers:

378 KU234536-KU234540.

379

380 Data Availability

381 The following information was supplied regarding data availability:

382 The raw data has been supplied as a Supplementary Information.

\section{References}

Abascal F, Zardoya R, and Telford MJ. 2010. TranslatorX: multiple alignment of nucleotide sequences guided by amino acid translations. Nucleic Acids Research 38:W7-13. DOI:10.1093/nar/gkq291:

Abascal F, Posada D, Knight RD, and Zardoya R. 2006. Parallel evolution of the genetic code in arthropod mitochondrial genomes. PLoS Biology 4:e127.

Abd-Rabou S, Shalaby H, Germain J-F, Ris N, Kreiter P, and Malausa T. 2012. Identification of mealybug pest species (Hemiptera: Pseudococcidae) in Egypt and France, using a DNA barcoding approach. Bulletin of Entomological Research 102:515-523.

Avise JC. 2009. Phylogeography: retrospect and prospect. Journal of Biogeography 36:3-15.

Boore JL. 1999. Animal mitochondrial genomes. Nucleic Acids Research 27:1767-1780. DOI:10.1093/nar/27.8.1767:

Brabec J, Kostadinova A, Scholz T, and Littlewood DTJ. 2015. Complete mitochondrial genomes and nuclear ribosomal RNA operons of two species of Diplostomum (Platyhelminthes: Trematoda): a molecular resource for taxonomy and molecular 
epidemiology of important fish pathogens. Parasites \& Vectors 8:1-11.

400 Cameron SL. 2014. Insect mitochondrial genomics: implications for evolution and phylogeny. Annual Review of Entomology 59:95-117. DOI:10.1146/annurev-ento-011613-162007:

402

403

404

405

406

407

408

409

410

411

412

413

414

415

416

417

418

419

420

421

Cameron SL, and Whiting MF. 2008. The complete mitochondrial genome of the tobacco hornworm, Manduca sexta, (Insecta: Lepidoptera: Sphingidae), and an examination of mitochondrial gene variability within butterflies and moths. Gene 408:112-123. DOI:10.1016/j.gene.2007.10.023:

Cassis G, and Schuh RT. 2012. Systematics, Biodiversity, Biogeography, and Host Associations of the Miridae (Insecta: Hemiptera: Heteroptera: Cimicomorpha). Annual Review of Entomology 57:377-404. DOI:10.1146/annurev-ento-121510-133533:

Dai X, Xun H, Chang J, Zhang J, Hu B, Li H, Yuan X, and Cai W. 2012. The complete mitochondrial genome of the plant bug Nesidiocoris tenuis (Reuter)(Hemiptera: Miridae: Bryocorinae: Dicyphini). Zootaxa:30-44.

Duchêne S, Archer FI, Vilstrup J, Caballero S, and Morin PA. 2011. Mitogenome Phylogenetics: The Impact of Using Single Regions and Partitioning Schemes on Topology, Substitution Rate and Divergence Time Estimation. PLoS ONE 6:e27138. DOI:10.1371/journal.pone.0027138:

Foottit R, Maw H, Von Dohlen C, and Hebert P. 2008. Species identification of aphids (Insecta: Hemiptera: Aphididae) through DNA barcodes. Molecular Ecology Resources 8:11891201.

Hall TA. 1999. BioEdit: a user-friendly biological sequence alignment editor and analysis program for Windows 95/98/NT. Nucleic Acids Symposium Series. p 95-98.

Hassanin A, Leger N, and Deutsch J. 2005. Evidence for multiple reversals of asymmetric 
422

423

424

425

426

427

428

mutational constraints during the evolution of the mitochondrial genome of Metazoa, and consequences for phylogenetic inferences. Systematic Biology 54:277-298. DOI:10.1080/10635150590947843:

Havird JC, and Santos SR. 2014. Performance of Single and Concatenated Sets of Mitochondrial Genes at Inferring Metazoan Relationships Relative to Full Mitogenome Data. PLoS ONE 9:e84080. DOI:10.1371/journal.pone.0084080:

Hebert PD, Ratnasingham S, and de Waard JR. 2003. Barcoding animal life: cytochrome c oxidase subunit 1 divergences among closely related species. Proceedings of the Royal Society of London B: Biological Sciences 270:S96-S99.

Jinbo U, Kato T, and Ito M. 2011. Current progress in DNA barcoding and future implications for Entomology. Entomological Science 14:107-124.

Jung S, Duwal RK, and Lee S. 2011. COI barcoding of true bugs (Insecta, Heteroptera). Molecular Ecology Resources 11:266-270. DOI:10.1111/j.1755-0998.2010.02945.x:

Jung S, and Lee S. 2012. Molecular phylogeny of the plant bugs (Heteroptera: Miridae) and the evolution of feeding habits. Cladistics 28:50-79. DOI:10.1111/j.1096-0031.2011.00365.x:

Katoh K, and Standley DM. 2013. MAFFT multiple sequence alignment software version 7: improvements in performance and usability. Molecular Biology and Evolution 30:772780.

Kubisz D, Kajtoch Ł, Mazur M, and Rizun V. 2012. Molecular barcoding for central-eastern European Crioceris leaf-beetles (Coleoptera: Chrysomelidae). Open Life Sciences 7:6976.

Lanfear R, Calcott B, Ho SY, and Guindon S. 2012. Partitionfinder: combined selection of partitioning schemes and substitution models for phylogenetic analyses. Molecular 
Biology and Evolution 29:1695-1701. DOI:10.1093/molbev/mss020:

446

447

448

449

450

451

452

453

454

455

456

457

458

459

460

461

462

463

464

465

466

467

Lee W, Park J, Lee GS, Lee S, and Akimoto S. 2013. Taxonomic status of the Bemisia tabaci complex (Hemiptera: Aleyrodidae) and reassessment of the number of its constituent species. PLoS ONE 8:e63817.

Levkanicova Z, and Bocak L. 2009. Identification of net-winged beetle larvae (Coleoptera: Lycidae) using three mtDNA fragments: a comparison of their utility. Systematic Entomology 34:210-221.

Li F, Zhang H, Wang W, Weng H, and Meng Z. 2016. Complete mitochondrial genome of the Japanese pine sawyer, Monochamus alternatus (Coleoptera: Cerambycidae). Mitochondrial DNA Part A 27:1144-1145.

Lu Y, Wu K, Jiang Y, Xia B, Li P, Feng H, Wyckhuys KA, and Guo Y. 2010. Mirid bug outbreaks in multiple crops correlated with wide-scale adoption of Bt cotton in China. Science 328:1151-1154.

MeiYan C, HuiLin H, Qiang G, CongHui Y, Qian J, Jun L, FuQiang C, ChunSheng W, and AiBing Z. 2012. Effects of different evolution models on DNA barcoding evaluated with the Noctuidae from Wuling Mountain, Hebei, northern China. Acta Entomologica Sinica 55:1193-1204.

Miller MA, Pfeiffer W, and Schwartz T. 2010. Creating the CIPRES Science Gateway for inference of large phylogenetic trees. Gateway Computing Environments Workshop (GCE), 2010: Gateway Computing Environments Workshop (GCE), 2010. p 1-8.

Mitchell A, Keena MA, Gopurenko D, Boykin LM, Armstrong KF, Pogue MG, Lima J, Floyd R, Hanner RH, and Humble LM. 2010. Towards a global barcode library for Lymantria (Lepidoptera: Lymantriinae) tussock moths of biosecurity concern. PLoS ONE 5:e14280. 
468 Monaghan MT, Balke M, Gregory TR, and Vogler AP. 2005. DNA-based species delineation in

469

470

471

472

473

474

475

476

477

478

479

480

481

482

483

484

485

486

487

488

489

490

tropical beetles using mitochondrial and nuclear markers. Philosophical Transactions of the Royal Society of London B: Biological Sciences 360:1925-1933.

Nadimi M, Daubois L, and Hijri M. 2016. Mitochondrial comparative genomics and phylogenetic signal assessment of mtDNA among arbuscular mycorrhizal fungi. Molecular Phylogenetics and Evolution 98:74-83.

Okimoto R, Macfarlane J, Clary D, and Wolstenholme D. 1992. The mitochondrial genomes of two nematodes, Caenorhabditis elegans and Ascaris suum. Genetics 130:471.

Park DS, Foottit R, Maw E, and Hebert PD. 2011. Barcoding bugs: DNA-based identification of the true bugs (Insecta: Hemiptera: Heteroptera). PLoS ONE 6:e18749.

Park DS, Leem YJ, Hahn K-W, Suh SJ, Hong KJ, and Oh HW. 2010. Molecular identification of mealybugs (Hemiptera: Pseudococcidae) found on Korean pears. Journal of Economic Entomology 103:25-33.

Perna NT, and Kocher TD. 1995. Patterns of nucleotide composition at fourfold degenerate sites of animal mitochondrial genomes. Journal of Molecular Evolution 41:353-358.

Posada D. 2008. jModelTest: phylogenetic model averaging. Molecular Biology and Evolution $25: 1253-1256$.

Raupach MJ, Astrin JJ, Hannig K, Peters MK, Stoeckle MY, and Wägele JW. 2010. Molecular species identification of Central European ground beetles(Coleoptera: Carabidae) using nuclear rDNA expansion segments and DNA barcodes. Frontiers in Zoology 7:1-15.

Raupach MJ, Hendrich L, Küchler SM, Deister F, Morinière J, and Gossner MM. 2014. Building-up of a DNA barcode library for true bugs (insecta: hemiptera: heteroptera) of Germany reveals taxonomic uncertainties and surprises. PLoS ONE 9:e106940. 
491

492

493

494

495

496

497

498

499

500

501

502

503

504

505

506

507

508

509

510

511

512

513

DOI:10.1371/journal.pone.0106940:

Roehrdanz R, Cameron SL, Toutges M, and Wichmann SS. 2016. The complete mitochondrial genome of the tarnished plant bug, Lygus lineolaris (Heteroptera: Miridae). Mitochondrial DNA Part A 27:48-49. DOI:10.3109/19401736.2013.869689:

Ronquist F, Teslenko M, van der Mark P, Ayres DL, Darling A, Hohna S, Larget B, Liu L, Suchard MA, and Huelsenbeck JP. 2012. MrBayes 3.2: efficient Bayesian phylogenetic inference and model choice across a large model space. Systematic Biology 61:539-542. DOI:10.1093/sysbio/sys029:

Schmidt BC, and Sperling FA. 2008. Widespread decoupling of mtDNA variation and species integrity in Grammia tiger moths (Lepidoptera: Noctuidae). Systematic Entomology 33:613-634.

Seixas VC, Paiva PC, and Russo CAM. 2016. Complete mitochondrial genomes are not necessarily more informative than individual mitochondrial genes to recover a wellestablished annelid phylogeny. Gene Reports 5:10-17.

Sheffield NC, Song H, Cameron SL, and Whiting MF. 2008. A comparative analysis of mitochondrial genomes in Coleoptera (Arthropoda: Insecta) and genome descriptions of six new beetles. Molecular Biology and Evolution 25:2499-2509.

Simon C, Buckley TR, Frati F, Stewart JB, and Beckenbach AT. 2006. Incorporating molecular evolution into phylogenetic analysis, and a new compilation of conserved polymerase chain reaction primers for animal mitochondrial DNA. Annual Review of Ecology, Evolution, and Systematics 37:545-579. DOI:10.1146/annurev.ecolsys.37.091305.110018:

Stamatakis A. 2014. RAxML version 8: a tool for phylogenetic analysis and post-analysis of large phylogenies. Bioinformatics 30:1312-1313. DOI:10.1093/bioinformatics/btu033: 
514 Tamura K, Stecher G, Peterson D, Filipski A, and Kumar S. 2013. MEGA6: molecular

515 evolutionary genetics analysis version 6.0. Molecular Biology and Evolution 30:27252729. DOI:10.1093/molbev/mst197:

517 Wang P, Li H, Wang Y, Zhang JH, Dai X, Chang J, Hu BW, and Cai WZ. 2014a. The

518

519

520

521

522

523

524

525

526

527

528

529

530

531

532

533

534

535

536

mitochondrial genome of the plant bug Apolygus lucorum (Hemiptera: Miridae):

presently known as the smallest in Heteroptera. Insect Science 21:159-173.

DOI:10.1111/1744-7917.12029:

Wang Y, Chen J, Jiang L-Y, and Qiao GX. 2015. Hemipteran mitochondrial genomes: Features, structures and implications for phylogeny. International Journal of Molecular Sciences $16: 12382-12404$.

Wang Y, Li H, Wang P, Song F, and Cai WZ. 2014b. Comparative mitogenomics of plant bugs (Hemiptera: Miridae): identifying the AGG codon reassignments between Serine and Lysine. PLoS ONE 9:e101375. DOI:10.1371/journal.pone.0101375:

Wang Y, Li H, Xun H, and Cai W. 2016a. Complete mitochondrial genome sequence of the plant bug Adelphocoris fasciaticollis (Hemiptera: Heteroptera: Miridae). Mitochondrial DNA Part A 27:222-223. DOI:10.3109/19401736.2014.880898:

Wang YT, Liu YX, Tong XL, Ren QP, and Jiang GF. 2016b. The complete mitochondrial genome of the longhorn beetle, Massicus raddei. Mitochondrial DNA Part A 27:209-211.

Wheeler AG. 2001. Biology of the plant bugs (Hemiptera: Miridae): pests, predators, opportunists. New York: Cornell University Press.

Wiemers M, and Fiedler K. 2007. Does the DNA barcoding gap exist?-a case study in blue butterflies (Lepidoptera: Lycaenidae). Frontiers in Zoology 4:8.

Wolff JN, Camus MF, Clancy DJ, and Dowling DK. 2016. Complete mitochondrial genome 
537

538

sequences of thirteen globally sourced strains of fruit fly (Drosophila melanogaster) form a powerful model for mitochondrial research. Mitochondrial DNA Part A 27:4672-4674.

Xia X. 2013. DAMBE5: a comprehensive software package for data analysis in molecular biology and evolution. Molecular Biology and Evolution 30:1720-1728. DOI:10.1093/molbev/mst064:

Ye F, Liu T, Zhu W, and You P. 2015. Complete mitochondrial genome of Whitmania laevis (Annelida, Hirudinea) and comparative analyses within Whitmania mitochondrial genomes. Belgian Journal of Zoology 145:115-129.

Yu H, Kong L, and Li Q. 2016. Evaluation of the efficacy of twelve mitochondrial proteincoding genes as barcodes for mollusk DNA barcoding. Mitochondrial DNA Part A 27:1336-1339.

Yuan ML, Zhang QL, Guo ZL, Wang J, and Shen YY. 2015a. Comparative mitogenomic analysis of the superfamily Pentatomoidea (Insecta: Hemiptera: Heteroptera) and phylogenetic implications. BMC Genomics 16:460. DOI:10.1186/s12864-015-1679-x:

Yuan ML, Zhang QL, Guo ZL, Wang J, and Shen YY. 2015b. The complete mitochondrial genome of Corizus tetraspilus (Hemiptera: Rhopalidae) and phylogenetic analysis of Pentatomomorpha. PLoS ONE 10:e0129003. DOI:10.1371/journal.pone.0129003:

Yuan ML, Zhang QL, Zhang L, Guo ZL, Liu YJ, Shen YY, and Shao R., 2016. High-level phylogeny of the Coleoptera inferred with mitochondrial genome sequences. Molecular Phylogenetics and Evolution 104: 99-111.

Zhang B, Zhou MQ, Wang J, Pu Y, Zhang L, and Yuan ML. 2016. Species checklist and research status of alfalfa insect pests reported in China. Pratacultural Science 33:785-812. 
561 Supplementary Information

562 Figure S1: Base composition of 15 mirid mitochondrial genomes.

563 Figure S2: Bayesian phylogeny of mirid bugs using each of 13 protein-coding genes, $r r n L$,

564 rrnS and 22 tRNA genes. Numbers on branches are Bayesian posterior probabilities.

565 Figure S3: Maximum likelihood phylogeny of mirid bugs using each of 13 protein-coding

566 genes, $\boldsymbol{r r n L}, \boldsymbol{r r n S}$ and 22 tRNA genes. Numbers on branches are bootstrap support values.

567 Figure S4: Phylogeny of eleven mirid bugs based on the cox1-barcode sequences. Numbers

568 on branches are Bayesian posterior probabilities (left) and bootstrap values (right).

569

570

Table S1: Primers used in this study.

Table S2: Evolutionary models for each dataset. The best partitioning schemes and

substitution models were selected by PartitionFinder for the P123 and P123RT datasets, and each

of 13 PCGs. The best substitution models for $r r n L, r r n S, 22$ tRNAs and coxl-barcode sequences

were determined by jModelTest.

Table S3: The annotation and organization of the mitochondrial genomes of five mirid species sequenced in this study.

Table S4: Codon usage in the 15 mirid mitochondrial genomes.

Table S5: Length variations (bp) of 13 protein-coding genes, $r r n L$ and $r r n S$ among the 15

mirid mitogenomes.

Table S6: Evolutionary analyses of cox 1 -barcode sequences from the 15 mirid

mitochondrial genomes. 
582 Table S7: Evolutionary analyses of $\operatorname{cox} 1$-barcode sequences of Miridae available in 583 GenBank.

584

585 Raw data

586 Raw data-Alignment of protein-coding genes, rRNA genes and tRNAs used in this study.

587 Raw data-Mitochondrial genome sequences of five mirids sequenced in this study. 


\section{Figure 1 (on next page)}

Figure 1: Putative secondary structures of the 22 tRNA genes identified in the mitochondrial genome of Adelphocoris lineolatus.

(A) trnl, (B) trnQ, (C) trnM, (D) trnW, (E) trnC, (F) trnY, (G) trnL2, (H) trnK, (I) trnD, (J) trnG, (K) trnA, (L) trnR, (M) trnN, (N) trnS1, (O) trnE, (P) trnF, (Q) trnH, (R) trnT, (S) trnP, (T) trnS2, (U) trnL1, (V) trnV. All tRNA genes are shown in the order of occurrence in the mitochondrial genome starting from trnl. The nucleotides showing $100 \%$ identity in the 15 mirid mitochondrial genomes are marked with green color, and the variable region are marked with red color. Bars indicate Watson-Crick base pairings, and dots between $\mathrm{G}$ and $\mathrm{U}$ pairs mark canonical base pairings in tRNA. 
Figure 2 (on next page)

Figure 2: The K2P genetic distance, $\mathrm{Ka}$ and $\mathrm{Ka} / \mathrm{Ks}$ of 13 protein-coding genes among the 15 mirid mitochondrial genomes.

(A) K2P, the Kimura-2- parameter distance; (B) Ka, the number of nonsynonymous substitutions per nonsynonymous site; (C) Ka/Ks. Ks, the number of synonymous substitutions per synonymous site. 
Miridae

PAdelphocoris

- Adelphocoris lineolatus
- Mirinae

- Mirini

- Lygus Manuscript to beabeliphedris fasciaticollis

- Adelphocoris suturalis - Apolygus lucorum
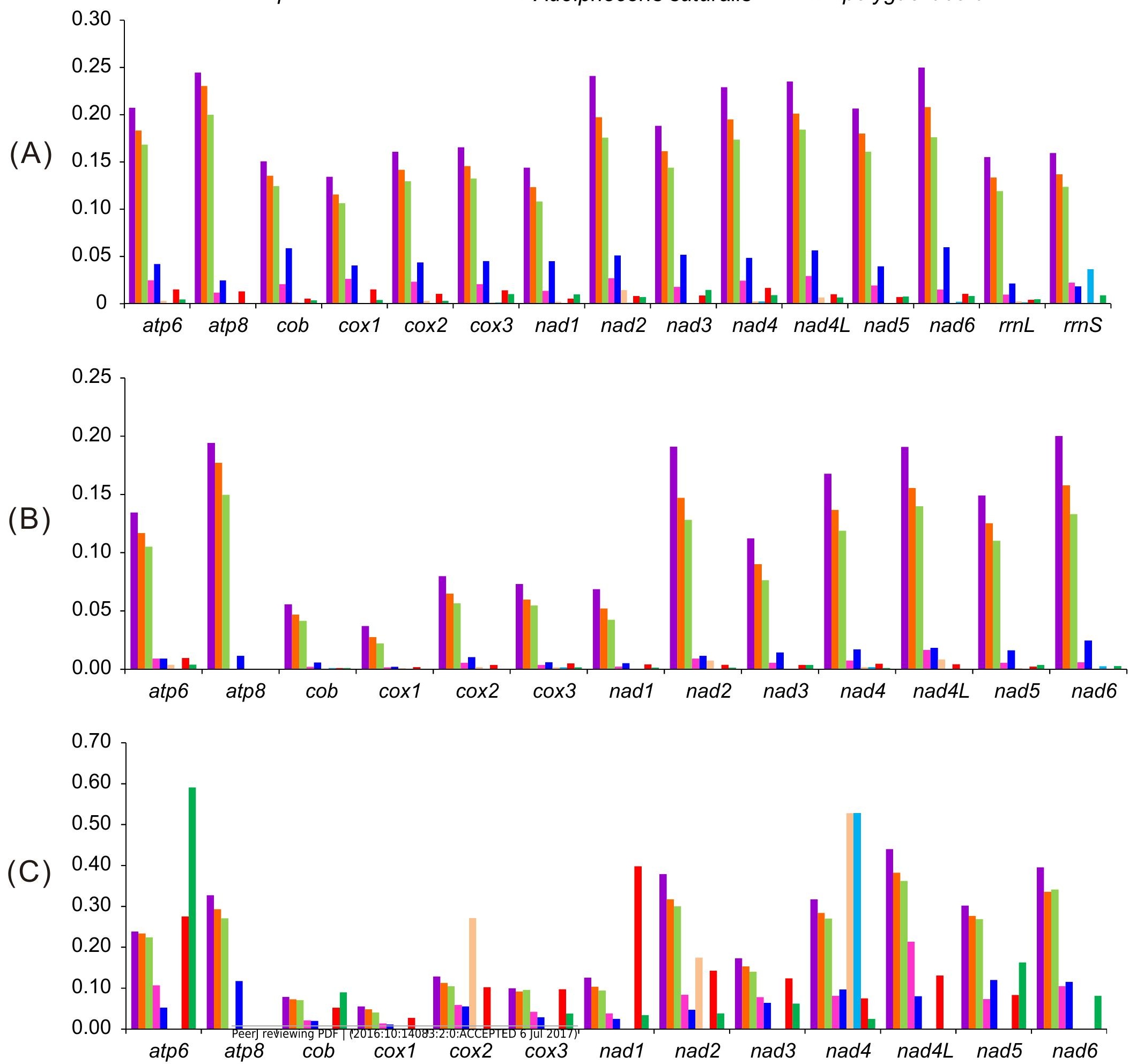


\section{Figure 3 (on next page)}

Figure 3: The mitochondrial phylogeny of eleven mirid bugs based on the two combined datasets: (A) P123 and (B) P123RT.

Numbers on branches are Bayesian posterior probabilities (PP, left) and Bootstrap values (BS, right). Asterisk (*) indicates PP $=1.0$ and $B S=100$. Species sequenced in the present study are bold. 


\section{Table 1 (on next page)}

Table 1: List of mirid species analyzed in the study. 
1 Table 1: List of mirid species analyzed in the study.

\begin{tabular}{|c|c|c|c|c|c|c|c|}
\hline Subfamily & Species & $\begin{array}{l}\text { Size } \\
\text { (bp) }\end{array}$ & $\begin{array}{c}\mathrm{A}+\mathrm{T} \\
\%\end{array}$ & $\begin{array}{l}\text { AT- } \\
\text { skew }\end{array}$ & $\begin{array}{l}\text { GC- } \\
\text { skew }\end{array}$ & $\begin{array}{l}\text { GenBank } \\
\text { Accession }\end{array}$ & References \\
\hline $\begin{array}{l}\text { Bryocorina } \\
\text { e }\end{array}$ & Nesidiocoris tenuis & 17544 & 75.0 & 0.10 & -0.11 & NC_022677 & Dai et al. 2012 \\
\hline \multirow[t]{14}{*}{ Mirinae } & Adelphocoris fasciaticollis & 15434 & 77.4 & 0.16 & -0.22 & KJ001714 & Wang et al. 2016 \\
\hline & Adelphocoris fasciaticollis_Yuan* & 13587 & 77.0 & 0.17 & -0.21 & KU234536 & This study \\
\hline & Adelphocoris lineolatus & 15595 & 77.1 & 0.16 & -0.21 & KJ020286 & Wang et al. $2014 \mathrm{~b}$ \\
\hline & Adelphocoris lineolatus_Yuan & 15433 & 76.9 & 0.16 & -0.21 & KU234537 & This study \\
\hline & Adelphocoris nigritylus* & 14522 & 77.2 & 0.17 & -0.21 & KJ020287 & Wang et al. 2014b \\
\hline & Adelphocoris suturalis* & 14327 & 76.8 & 0.17 & -0.20 & KJ020288 & Wang et al. 2014b \\
\hline & Adelphocoris suturalis_Yuan* & 14106 & 76.8 & 0.17 & -0.21 & KU234538 & This study \\
\hline & Apolygus lucorum & 14768 & 76.8 & 0.12 & -0.12 & NC_023083 & Wang et al. $2014 \mathrm{a}$ \\
\hline & Apolygus lucorum_Yuan & 15647 & 76.8 & 0.11 & -0.12 & KU234539 & This study \\
\hline & Lygus hesperus & 17747 & 75.3 & 0.14 & -0.19 & NC_024641 & Unpublished \\
\hline & Lygus lineolaris & 17027 & 75.9 & 0.13 & -0.18 & NC_021975 & $\begin{array}{l}\text { Roehrdanz et al. } \\
2016\end{array}$ \\
\hline & Lygus pratenszs* & 14239 & 75.6 & 0.15 & -0.18 & KU234540 & This study \\
\hline & Lygus rugulipennis* & 15819 & 75.5 & 0.14 & -0.18 & KJ170898 & Wang et al. 2014b \\
\hline & Trigonotylus caelestialium* & 15095 & 74.9 & 0.14 & -0.13 & KJ170899 & Wang et al. $2014 b$ \\
\hline
\end{tabular}


$2 *$ incomplete mitochondrial genomes. 


\section{Table 2 (on next page)}

Table 2: Number of variable sites and number of informative sites in Miridae. 
1 Table 2: Number of variable sites and number of informative sites in Miridae.

\begin{tabular}{|c|c|c|c|c|c|c|c|c|c|c|}
\hline \multirow[b]{2}{*}{ Gene } & \multicolumn{2}{|c|}{ Miridae } & \multicolumn{2}{|c|}{ Mirinae } & \multicolumn{2}{|c|}{ Mirini } & \multicolumn{2}{|c|}{ Adelphocoris } & \multicolumn{2}{|c|}{ Lygus } \\
\hline & $\begin{array}{l}\text { Number of } \\
\text { variable } \\
\text { sites (\%) }\end{array}$ & $\begin{array}{c}\text { Number } \\
\text { of } \\
\text { informativ } \\
\text { e sites (\%) }\end{array}$ & $\begin{array}{l}\text { Number of } \\
\text { variable } \\
\text { sites }(\%)\end{array}$ & $\begin{array}{l}\text { Number of } \\
\text { informativ } \\
\text { e sites }(\%)\end{array}$ & $\begin{array}{l}\text { Number of } \\
\text { variable } \\
\text { sites }(\%)\end{array}$ & $\begin{array}{l}\text { Number of } \\
\text { informativ } \\
\text { e sites }(\%)\end{array}$ & $\begin{array}{c}\text { Number } \\
\text { of } \\
\text { variable } \\
\text { sites }(\%)\end{array}$ & $\begin{array}{c}\text { Number } \\
\text { of } \\
\text { informativ } \\
\text { e sites (\%) }\end{array}$ & $\begin{array}{c}\text { Number of } \\
\text { variable } \\
\text { sites }(\%)\end{array}$ & $\begin{array}{c}\text { Number } \\
\text { of } \\
\text { informativ } \\
\text { e sites (\%) }\end{array}$ \\
\hline atp6 & $\begin{array}{c}319 \\
(47.47)\end{array}$ & $\begin{array}{c}212 \\
(31.55)\end{array}$ & $260(38.86)$ & $\begin{array}{c}203 \\
(30.34)\end{array}$ & $\begin{array}{c}227 \\
(33.93)\end{array}$ & $\begin{array}{c}199 \\
(29.75)\end{array}$ & $39(5.83)$ & $23(3.44)$ & $50(7.47)$ & $9(1.35)$ \\
\hline $\operatorname{atp} 8$ & $84(52.83)$ & $60(37.74)$ & $74(46.54)$ & $56(35.22)$ & $58(36.48)$ & $56(35.22)$ & $4(2.56)$ & $3(1.92)$ & $7(4.40)$ & $2(1.26)$ \\
\hline$c o b$ & $\begin{array}{c}412 \\
(36.43)\end{array}$ & $\begin{array}{c}273 \\
(24.14)\end{array}$ & $350(30.95)$ & $\begin{array}{c}263 \\
(23.25)\end{array}$ & $\begin{array}{c}296 \\
(26.17)\end{array}$ & $\begin{array}{c}254 \\
(22.46)\end{array}$ & $51(4.51)$ & $39(3.45)$ & $\begin{array}{c}117 \\
(10.34)\end{array}$ & $19(1.68)$ \\
\hline $\operatorname{cox} 1$ & $\begin{array}{c}534 \\
(34.83)\end{array}$ & $\begin{array}{c}344 \\
(22.44)\end{array}$ & $425(27.72)$ & $\begin{array}{c}322 \\
(21.00)\end{array}$ & $\begin{array}{c}357 \\
(23.29)\end{array}$ & $\begin{array}{c}314 \\
(20.48)\end{array}$ & $87(5.68)$ & $60(3.91)$ & $110(7.18)$ & $23(1.50)$ \\
\hline $\operatorname{cox} 2$ & $\begin{array}{c}267 \\
(39.38)\end{array}$ & $\begin{array}{c}185 \\
(27.29)\end{array}$ & $219(32.30)$ & $\begin{array}{c}168 \\
(24.78)\end{array}$ & $\begin{array}{c}183 \\
(26.99)\end{array}$ & $\begin{array}{c}164 \\
(24.19)\end{array}$ & $37(5.46)$ & $23(3.39)$ & $53(7.82)$ & $10(1.47)$ \\
\hline $\operatorname{cox} 3$ & $\begin{array}{c}311 \\
(39.72)\end{array}$ & $\begin{array}{c}204 \\
(26.05)\end{array}$ & $252(32.18)$ & $\begin{array}{c}191 \\
(24.39)\end{array}$ & $\begin{array}{c}212 \\
(27.08)\end{array}$ & $\begin{array}{c}189 \\
(24.14)\end{array}$ & $36(4.06)$ & $25(3.19)$ & $62(7.92)$ & $11(1.40)$ \\
\hline nad1 & $\begin{array}{c}343 \\
(37.12)\end{array}$ & $\begin{array}{c}215 \\
(23.27)\end{array}$ & $274(29.65)$ & $\begin{array}{c}194 \\
(21.00)\end{array}$ & $\begin{array}{c}215 \\
(23.27)\end{array}$ & $\begin{array}{c}190 \\
(20.56)\end{array}$ & $27(2.92)$ & $19(2.06)$ & $75(8.12)$ & $12(1.30)$ \\
\hline nad2 & $\begin{array}{c}562 \\
(55.92)\end{array}$ & $\begin{array}{c}352 \\
(35.02)\end{array}$ & $441(43.88)$ & $\begin{array}{c}324 \\
(32.24)\end{array}$ & $\begin{array}{c}363 \\
(36.12)\end{array}$ & $\begin{array}{c}316 \\
(31.44)\end{array}$ & $67(6.75)$ & $32(3.22)$ & $91(9.05)$ & $11(1.09)$ \\
\hline nad3 & $\begin{array}{c}168 \\
(47.86)\end{array}$ & $\begin{array}{c}103 \\
(29.34)\end{array}$ & $132(37.61)$ & $96(27.35)$ & $\begin{array}{c}109 \\
(31.05)\end{array}$ & $94(26.78)$ & $14(3.99)$ & $10(2.85)$ & $32(9.12)$ & 7 (1.99) \\
\hline
\end{tabular}




\begin{tabular}{|c|c|c|c|c|c|c|c|c|c|c|}
\hline nad4 & $\begin{array}{c}703 \\
(52.96)\end{array}$ & $\begin{array}{c}450 \\
(33.86)\end{array}$ & $570(42.99)$ & $\begin{array}{c}404 \\
(30.47)\end{array}$ & $\begin{array}{c}452 \\
(34.09)\end{array}$ & $\begin{array}{c}399 \\
(30.09)\end{array}$ & $74(5.58)$ & $46(3.47)$ & $112(8.45)$ & $23(1.73)$ \\
\hline $\operatorname{nad} 4 \mathrm{~L}$ & $\begin{array}{c}167 \\
(54.58)\end{array}$ & $\begin{array}{c}101 \\
(33.01)\end{array}$ & $130(42.48)$ & $94(30.72)$ & $\begin{array}{c}105 \\
(34.31)\end{array}$ & $94(30.72)$ & $20(6.60)$ & $13(4.29)$ & $30(9.90)$ & $3(0.99)$ \\
\hline nad5 & $\begin{array}{c}828 \\
(48.51)\end{array}$ & $\begin{array}{c}541 \\
(31.69)\end{array}$ & $678(39.72)$ & $\begin{array}{c}506 \\
(29.64)\end{array}$ & $\begin{array}{c}550 \\
(32.22)\end{array}$ & $\begin{array}{c}496 \\
(29.06)\end{array}$ & 69 (4.07) & $56(3.30)$ & $120(7.07)$ & $19(1.12)$ \\
\hline nad6 & $\begin{array}{c}289 \\
(57.68)\end{array}$ & $\begin{array}{c}172 \\
(34.33)\end{array}$ & $228(46.63)$ & $\begin{array}{c}155 \\
(31.70)\end{array}$ & $\begin{array}{c}172 \\
(35.17)\end{array}$ & $\begin{array}{c}151 \\
(30.88)\end{array}$ & $18(3.68)$ & $9(1.84)$ & $51(10.49)$ & $7(1.44)$ \\
\hline$r r n L$ & $\begin{array}{c}501 \\
(39.60)\end{array}$ & $\begin{array}{c}321 \\
(25.38)\end{array}$ & $388(30.77)$ & $\begin{array}{c}285 \\
(22.60)\end{array}$ & $\begin{array}{c}301 \\
(23.91)\end{array}$ & $\begin{array}{c}283 \\
(22.48)\end{array}$ & $28(2.27)$ & $17(1.38)$ & $47(3.75)$ & $9(0.72)$ \\
\hline$r r n S$ & $\begin{array}{c}494 \\
(55.01)\end{array}$ & $\begin{array}{c}211 \\
(23.50)\end{array}$ & $205(23.06)$ & $\begin{array}{c}198 \\
(22.27)\end{array}$ & $\begin{array}{c}205 \\
(23.16)\end{array}$ & $\begin{array}{c}193 \\
(21.81)\end{array}$ & $36(4.47)$ & $12(1.49)$ & 34 (3.99) & $4(0.47)$ \\
\hline $\operatorname{cox} 1-$ & 221 & 135 & $176(26.75)$ & 125 & 142 & 121 & $28(4.26)$ & $24(3.65)$ & $48(7.29)$ & $13(1.98)$ \\
\hline $\begin{array}{l}\text { barcoding } \\
\text { sequences }\end{array}$ & (33.59) & $(20.52)$ & & (19.00) & (21.58) & (18.39) & & & & \\
\hline
\end{tabular}




\section{Table 3(on next page)}

Table 3: The phylogeny for the major clades of Miridae recovered by different mitochondrial datasets and analytical approaches. 
Table 3: The phylogeny for the major clades of Miridae recovered by different mitochondrial datasets and analytical

\begin{tabular}{|c|c|c|c|c|c|c|c|}
\hline Gene & $\begin{array}{c}\text { Adelphocori } \\
s \\
\end{array}$ & Lygus & $\mathrm{Nes}+(\operatorname{Tri}+(\operatorname{Ade}+(\operatorname{Apo}+\mathrm{Lys})))$ & $\begin{array}{c}\mathrm{Af}+\mathrm{A} \\
1 \\
\end{array}$ & $\begin{array}{c}(\mathrm{Af}+\mathrm{Al})+\mathrm{A} \\
\mathrm{n} \\
\end{array}$ & $\mathrm{An}+\mathrm{As}$ & $\begin{array}{c}\mathrm{Lr}+(\mathrm{Ll}+(\mathrm{Lh}+\mathrm{Lp}) \\
) \\
\end{array}$ \\
\hline atp6 & $\mathrm{M} / \mathrm{M}$ & $\mathrm{M} / \mathrm{M}$ & $\mathrm{N} / \mathrm{N}$ & $\mathrm{N} / \mathrm{N}$ & $\mathrm{N} / \mathrm{N}$ & $\mathrm{Y} / \mathrm{Y}$ & $\mathrm{Y} / \mathrm{N}$ \\
\hline atp 8 & $\mathrm{M} / \mathrm{M}$ & $\mathrm{M} / \mathrm{M}$ & $\mathrm{N} / \mathrm{N}$ & $\mathrm{N} / \mathrm{N}$ & $\mathrm{N} / \mathrm{N}$ & $\mathrm{N} / \mathrm{N}$ & $\mathrm{N} / \mathrm{N}$ \\
\hline$c o b$ & $\mathrm{M} / \mathrm{M}$ & $\mathrm{M} / \mathrm{M}$ & $\mathrm{N} / \mathrm{N}$ & $\mathrm{Y} / \mathrm{Y}$ & $\mathrm{N} / \mathrm{N}$ & $\mathrm{N} / \mathrm{N}$ & $\mathrm{Y} / \mathrm{Y}$ \\
\hline $\operatorname{cox} 1$ & $\mathrm{M} / \mathrm{M}$ & $\mathrm{M} / \mathrm{M}$ & $\mathrm{Y} / \mathrm{N}$ & $\mathrm{N} / \mathrm{Y}$ & $\mathrm{N} / \mathrm{N}$ & $\mathrm{Y} / \mathrm{Y}$ & $\mathrm{N} / \mathrm{Y}$ \\
\hline $\operatorname{cox} 2$ & $\mathrm{M} / \mathrm{M}$ & $\mathrm{M} / \mathrm{M}$ & $\mathrm{N} / \mathrm{N}$ & $\mathrm{Y} / \mathrm{Y}$ & $\mathrm{Y} / \mathrm{Y}$ & $\mathrm{N} / \mathrm{N}$ & $\mathrm{Y} / \mathrm{N}$ \\
\hline $\operatorname{cox} 3$ & $\mathrm{M} / \mathrm{M}$ & $\mathrm{M} / \mathrm{M}$ & $\mathrm{N} / \mathrm{N}$ & $\mathrm{Y} / \mathrm{Y}$ & $\mathrm{Y} / \mathrm{Y}$ & $\mathrm{N} / \mathrm{N}$ & $\mathrm{Y} / \mathrm{Y}$ \\
\hline nadl & $\mathrm{M} / \mathrm{M}$ & $\mathrm{M} / \mathrm{M}$ & $\mathrm{N} / \mathrm{N}$ & $\mathrm{N} / \mathrm{N}$ & $\mathrm{N} / \mathrm{N}$ & $\mathrm{Y} / \mathrm{Y}$ & $\mathrm{Y} / \mathrm{Y}$ \\
\hline nad2 & $\mathrm{M} / \mathrm{M}$ & $\mathrm{M} / \mathrm{M}$ & $\mathrm{Y} / \mathrm{N}$ & $\mathrm{N} / \mathrm{N}$ & $\mathrm{N} / \mathrm{N}$ & $\mathrm{N} / \mathrm{N}$ & $\mathrm{N} / \mathrm{N}$ \\
\hline nad3 & $\mathrm{M} / \mathrm{M}$ & $\mathrm{M} / \mathrm{M}$ & $\mathrm{N} / \mathrm{N}$ & $\mathrm{N} / \mathrm{Y}$ & $\mathrm{N} / \mathrm{N}$ & $\mathrm{N} / \mathrm{N}$ & $\mathrm{N} / \mathrm{N}$ \\
\hline nad4 & $\mathrm{M} / \mathrm{M}$ & $\mathrm{M} / \mathrm{M}$ & $\mathrm{Y} / \mathrm{Y}$ & $\mathrm{Y} / \mathrm{Y}$ & $\mathrm{N} / \mathrm{N}$ & $\mathrm{Y} / \mathrm{Y}$ & $\mathrm{Y} / \mathrm{Y}$ \\
\hline$n a d 4 L$ & $\mathrm{M} / \mathrm{M}$ & $\mathrm{M} / \mathrm{P}$ & $\mathrm{N} / \mathrm{N}$ & $\mathrm{N} / \mathrm{N}$ & $\mathrm{N} / \mathrm{N}$ & $\mathrm{Y} / \mathrm{N}$ & $\mathrm{Y} / \mathrm{N}$ \\
\hline nad5 & $\mathrm{M} / \mathrm{M}$ & $\mathrm{M} / \mathrm{M}$ & $\mathrm{Y} / \mathrm{Y}$ & $\mathrm{Y} / \mathrm{Y}$ & $\mathrm{Y} / \mathrm{Y}$ & $\mathrm{N} / \mathrm{N}$ & $\mathrm{Y} / \mathrm{Y}$ \\
\hline nad6 & $\mathrm{M} / \mathrm{M}$ & $\mathrm{M} / \mathrm{M}$ & $\mathrm{N} / \mathrm{N}$ & $\mathrm{N} / \mathrm{N}$ & $\mathrm{N} / \mathrm{N}$ & $\mathrm{N} / \mathrm{N}$ & $\mathrm{Y} / \mathrm{Y}$ \\
\hline$r r n L$ & $\mathrm{M} / \mathrm{M}$ & $\mathrm{M} / \mathrm{M}$ & $\mathrm{Y} / \mathrm{Y}$ & $\mathrm{Y} / \mathrm{Y}$ & $\mathrm{Y} / \mathrm{Y}$ & $\mathrm{N} / \mathrm{N}$ & $\mathrm{Y} / \mathrm{Y}$ \\
\hline$r r n S$ & $\mathrm{M} / \mathrm{M}$ & $\mathrm{M} / \mathrm{M}$ & $\mathrm{N} / \mathrm{N}$ & $\mathrm{N} / \mathrm{N}$ & $\mathrm{N} / \mathrm{N}$ & $\mathrm{N} / \mathrm{N}$ & $\mathrm{N} / \mathrm{N}$ \\
\hline 22 tRNAs & $\mathrm{M} / \mathrm{M}$ & $\mathrm{M} / \mathrm{M}$ & $\mathrm{Y} / \mathrm{Y}$ & $\mathrm{Y} / \mathrm{Y}$ & $\mathrm{N} / \mathrm{N}$ & $\mathrm{N} / \mathrm{Y}$ & $\mathrm{Y} / \mathrm{Y}$ \\
\hline P123 & $\mathrm{M} / \mathrm{M}$ & $\mathrm{M} / \mathrm{M}$ & $\mathrm{Y} / \mathrm{Y}$ & $\mathrm{Y} / \mathrm{Y}$ & $\mathrm{N} / \mathrm{N}$ & $\mathrm{Y} / \mathrm{Y}$ & $\mathrm{Y} / \mathrm{Y}$ \\
\hline P123RT & $\mathrm{M} / \mathrm{M}$ & $\mathrm{M} / \mathrm{M}$ & $\mathrm{Y} / \mathrm{Y}$ & $\mathrm{Y} / \mathrm{Y}$ & $\mathrm{Y} / \mathrm{Y}$ & $\mathrm{N} / \mathrm{N}$ & $\mathrm{Y} / \mathrm{Y}$ \\
\hline $\begin{array}{l}\text { coxl-barcoding } \\
\text { sequences }\end{array}$ & $\mathrm{M} / \mathrm{M}$ & $\mathrm{M} / \mathrm{M}$ & $\mathrm{N} / \mathrm{N}$ & $\mathrm{Y} / \mathrm{Y}$ & $\mathrm{N} / \mathrm{N}$ & $\mathrm{Y} / \mathrm{Y}$ & $\mathrm{Y} / \mathrm{Y}$ \\
\hline
\end{tabular}

